\title{
Development of an In-orbit Refocusing Mechanism for the Meteosat Second Generation Weather Satellites
}

\author{
TNO Institute of Applied Physics (TNO-TPD) \\ P.O. Box 155, 2600 AD Delft, The Netherlands
}

P. Verhoeff, H.A. van Mierlo, B.C. Bram, J. Hopman, W.P. van Werhhoven. M. Le Kluse

\begin{abstract}
A Refocusing Mechanism (REM) has been designed and built for the SEVIRI instrument, the imager in the Meteosat Second Generation (MSG) satellite. The purpose of the mechanism is in-orbit focal adjustment of a mirror assembly which forms part of SEVIRI. As the MSG satellite observes the earth and its atmosphere from its geostationary orbit, the REM will he used to compensate for satellite structural distortions due to gravitational-, thermal and aging effects It is designed for frequent use. It enables in-orbit refocusing in $1.4 \mu \mathrm{m}$ steps over a range of 2 mm with virtually no spurious rotations and translations. The REM was designed to support a large $3.9 \mathrm{~kg}$ mirror module in an ARIANE 5 rocket launch environment without the use of clamping mechanisms. Further major design drivers were the limited volume and the strict mass requirement. The REM function is realized in two modules. A guide module, based on elastic elements provides the required stroke within the strict requirements on lateral deviation and tilt. An actuator module with a motor, a planetary gearbox and a recirculating rollerscrew provides the force for translation of the mirror assembly. Coupling of the two modules has heen realized by a dedicated leverarm structure.
\end{abstract}

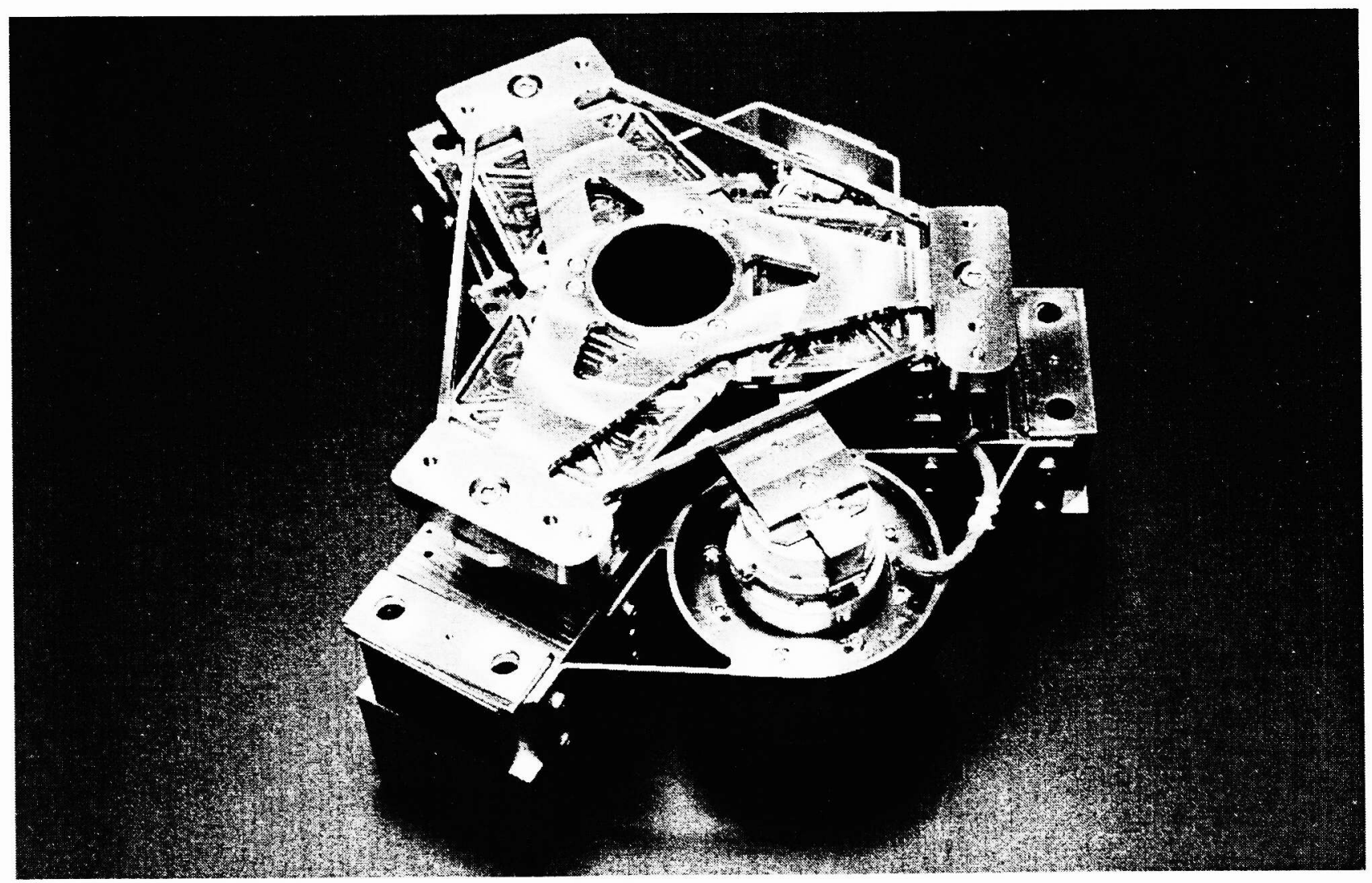




\section{INTRODUCTION}

The Meteosat Second Generation (MSG) program is being implemented by the European Space Agency (ESA), in cooperation with the European Organization for the Exploitation of Meteorological Satellites (EUMETSAT). Prime contractor of the MSG program is Aerospatiale in Cannes (Fr). The Imager of the MSG satellites, called Spinning Enhanced Visible and Infra-Red Imager (SEVIRI), is developed by Matra Marconi Space France (MMS-F).

The SEVIRI configuration is schematically presented in figure 1. The part of the Earth surface that can be monitored instantaneously is a few square kilometers. The complete Earth image is realized by scanning. The East-West direction is obtained by the spin motion of the satellite (100 RPM), the North-South direction is realized by a scanning mirror. The earth image is reflected via the scanning mirror (elliptically shaped, length approx. $80 \mathrm{~cm}$ ) on to the primary mirror and from there via the secondary and tertiary M2M3 mirror assembly on to the focal plane. The focal plane consists of 12 Infrared and Visible channels which are accommodated inside two 'warm' and 'cold' (95K) detection modules. The light passes through the REM envelope.

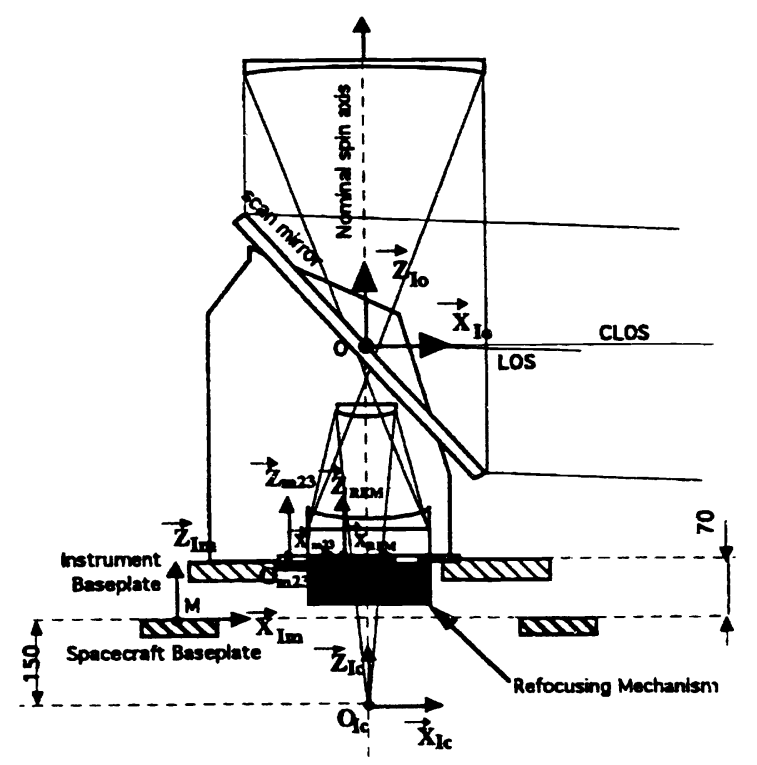

Fig. 1 SEVIRI configuration

The main functions of the REM are:

- Supporting the $3.9 \mathrm{~kg}$ M2M3 mirror assembly (CoG $110 \mathrm{~mm}$ above REM) and maintain its position with $\mu \mathrm{m}$ accuracy, during launch without a locking device and without using power.

- Adjustment of the M2M3 mirror assembly along a straight line on-ground and in-orbit over a range of $\pm 1 \mathrm{~mm}$ (lateral deviation/decenter: $<25 \mu \mathrm{m}$, spurious rotation/tilt: $<25 \mu \mathrm{rad})$.

- Maintain the M2M3 mirror assembly in a fixed position (in-focus stability $<10 \mu \mathrm{m}$, lateral deviation/decenter: $<25 \mu \mathrm{m}$, spurious rotation/tilt: $<25 \mu \mathrm{rad}$ ).

- Allow the passage of the optical beam from the tertiary mirror to the focal plane and provide straylight baffling.

The project is realized under the new (draft release 1994), more strict ESA ECSS requirements for mechanical design and -engineering. During the design phase, Finite Element Model (FEM) analysis has been performed using a detailed, representative model for the guide module. Furthermore, a detailed thermal model and a mathematical model to compute the Torque Margin begin- and end of life were made. 


\section{REQUIREMENTS AND CONSTRAINTS}

The most important requirements and (environmental) design constraints are summarized in table 1.

\begin{tabular}{|c|c|c|}
\hline Item: & Value: & Remark: \\
\hline Dimensions & $\begin{array}{l}\text { Diam. } 280 \mathrm{~mm} \times 123 \mathrm{~mm} \\
\text { Central hole diam. } 50 \mathrm{~mm} \\
\end{array}$ & \\
\hline Mass & $<7.9 \mathrm{~kg}$ & $\begin{array}{l}\text { Obtained after optimization (trade-off } \\
\text { eigenfrequency vs. mass). Original } \\
\text { mass requirement was }<3.6 \mathrm{~kg} \text {. }\end{array}$ \\
\hline Power consumption & $<14.5 \mathrm{~W}$ & $\begin{array}{l}\text { Peak power, at lowest operational } \\
\text { temperature. }\end{array}$ \\
\hline Stroke & $\pm 1.0 \mathrm{~mm}$ & \\
\hline Endstops & $\begin{array}{l} \pm 1.1 \mathrm{~mm} \\
\pm 1.2 \mathrm{~mm} \\
\end{array}$ & $\begin{array}{l}\text { Electrical, redundant } \\
\text { Mechanical }\end{array}$ \\
\hline Eigenfrequencies (launch condition) & $\begin{array}{l}>130 \mathrm{~Hz} \text { - in lateral direction } \\
>200 \mathrm{~Hz}-\text { in longitudinal direction }\end{array}$ & $\begin{array}{l}\text { Obtained after optimization (trade-off } \\
\text { eigenfrequency vs. mass). Original } \\
\text { eigenfrequency requirement was } \\
>200 \mathrm{~Hz} \text { in all directions. }\end{array}$ \\
\hline Lateral motion and rotations & $\begin{array}{l}< \pm 25 \mu \mathrm{m} \text { decenter } \\
< \pm 25 \mu \mathrm{rad} \text { spurious rotation }\end{array}$ & \\
\hline $\begin{array}{l}\text { Overall stability (including launch- and } \\
\text { zero gravity effect and thermoelastic } \\
\text { effects of the baseplate) }\end{array}$ & $\begin{array}{l}< \pm 10 \mu \mathrm{m} \text { in axial direction } \\
< \pm 25 \mu \mathrm{m} \text { decenter } \\
< \pm 25 \mu \text { rad spurious rotation }\end{array}$ & \\
\hline Resolution & $1.4 \mu \mathrm{m} \pm 30 \%$ & \\
\hline Linearity & $<10 \mu \mathrm{m}$ over the full stroke & \\
\hline Operational lifetime & 120 hours & $\begin{array}{l}7 \text { year in-orbit } \\
12 \text { year on-ground }\end{array}$ \\
\hline Operational temperature & +13 to $+43^{\circ} \mathrm{C}$ & \\
\hline Thermal gradient & $\pm 4^{\circ} \mathrm{C}$ - in lateral direction & \\
\hline Quasi-static loads & $\begin{array}{l} \pm 16 \mathrm{~g}-\text { in lateral direction } \\
\pm 30 \mathrm{~g}-\text { in longitudinal direction }\end{array}$ & Launch vibration (Qualification levels). \\
\hline Thermoelastic interface loads & $\begin{array}{l} \pm 270 \mathrm{~N}, 10 \mathrm{Nm} \\
\pm 10 \mathrm{~N}, 3 \mathrm{Nm} \\
\end{array}$ & $\begin{array}{l}\text { At baseplate interface. } \\
\text { At M2M3 mirror assembly interface. }\end{array}$ \\
\hline Operation duration & $\begin{array}{l}\geq 2 \text { full strokes continuously } \\
\geq 9 \text { min. against mechanical endstop }\end{array}$ & 16 minutes of continuous operation \\
\hline
\end{tabular}

Table 1 Refocusing mechanism requirements and environmental constraints.

\section{DESIGN}

The REM is designed in a modular way and consists of two separate modules which are related to the two main functions: guiding and actuation. Both modules are joined together via a dedicated leverarm, which besides for the coupling function also acts as a mean to reduce vibration loads on the Actuator Module.

The Support \& Guide (S\&G) Module guides the M2M3 mirror assembly along a straight line and provides adequate lateral stiffness, which is of primary importance in the launch vibration environment. The Actuator Module provides the actuation function, gives an adequate holding force and provides the required axial stiffness in the actuation direction during launch. In this section, descriptions of the design of the Support \& Guide- and the Actuator Modules and of the leverarm and the mathematical models used are given. 


\subsection{SUPPORT \& GUIDE MODULE}

For the required stroke, systems based on elastic elements can be applied. As a result of a trade-off between various concepts based on elastic elements, a concept based on six folded leafsprings was chosen for further design. Although there was a guide module design available from an earlier development with potential better capabilities in support (lateral stiffness) and performance (stroke $6 \mathrm{~mm}$, lateral decenter $15 \mathrm{~nm}$, lateral tilts $5 \mu \mathrm{rad}$ ), the Aristoteles Calibration Device', this design was not selected for the REM because of the envelope restrictions. Alternative concepts, such as membrane approaches were extensively studied but appeared not to be suitable. Especially the many over-constraints in a membrane system can be the cause of tilts far beyond the REM requirements.

The concept with the six folded leafsprings is shown in figure 2 . The figure shows the configuration of the leafsprings and the direction of motion of the rigid body that connects the leafsprings. Each folded leafspring constrains one degree of freedom. This is illustrated in figure 3 , showing the folded leafspring as two separate springs. A single leafspring can constrain three degrees of freedom. In the folded leafspring only the z-direction (degree of freedom) is constrained at the end of the system. Leafspring $\mathrm{B}$ cannot pass on the constraints $\mathrm{x}$ and rot $\mathrm{y}$ as provided by leaf spring $\mathrm{A}$.

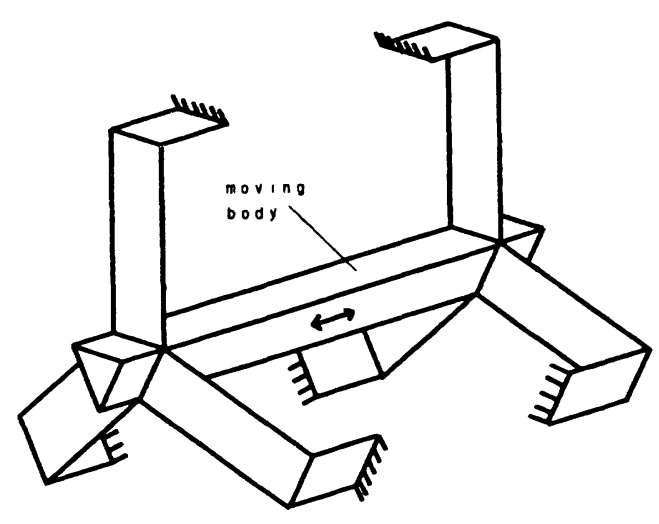

Figure 2 Six folded leafsprings

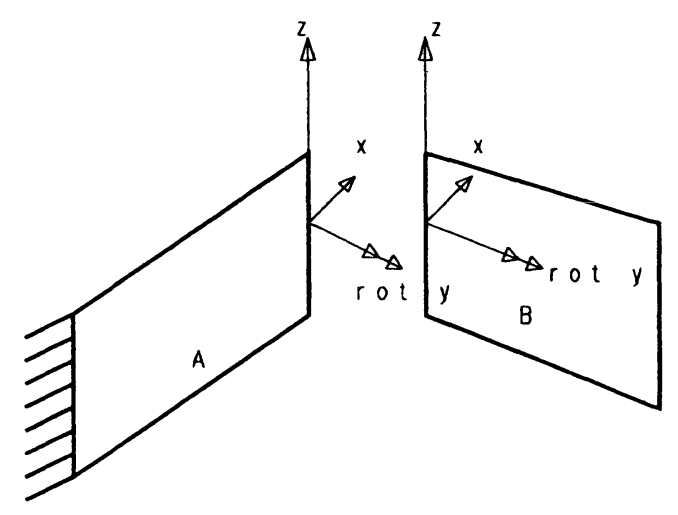

Figure 3 Constraint realized with folded leafspring

The six folded leafspring configuration provides six constraints while only five are needed for a guide system. As a result the moving body is overconstrained once. Analysis demonstrated that the sixth leafspring did not affect the pointing performance in a significant manner. Due to the symmetry, the configuration is insensitive for thermal effects. Changes in temperature have practically no impact on the performance because the thermal center (axis which maintains its position during temperature change) in the REM coincides with the geometrical center ${ }^{2}$. Analysis demonstrated that the thermal gradients which can be expected (see table 1) cause a lateral displacement of less than $1 \mu \mathrm{m}$ in the REM configuration, which is an effect that can be neglected.

The selected leafspring configuration facilitates the beam passage and the realization of a minimum volume. The Actuator Module could be accommodated practically inside the Support \& Guide Module envelope. The realized design is presented in figure 4 (exploded view of the REM) and figure 5 (cross-sectional view, showing the accommodation of the Actuator Module, the Lever Arm, a Monolithic Leafspring and the Baffle for optical beam passage). Figure 4 shows how the six folded leafsprings are realized in three monolithic blocks. The applied material for the leafsprings is the titanium alloy $\mathrm{TiAl}_{6} \mathrm{~V}_{4}$ which was machined by spark-erosion. The mass of the Support \& Guide Module was reduced as much as possible while still satisfying the required eigenfrequencies and maintaining adequate safety margins by FE-modeling. 


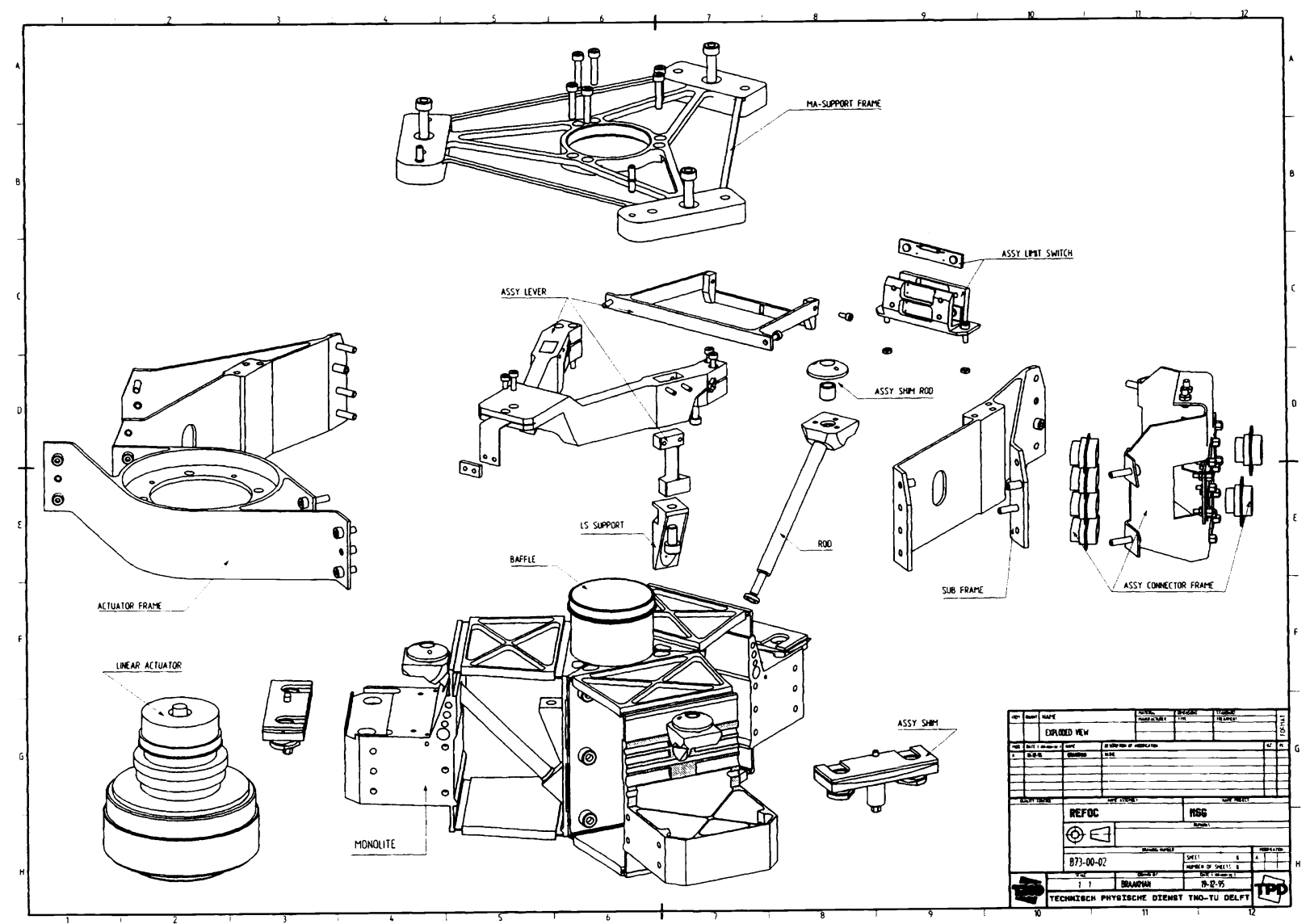

Figure 4 Exploded view of the REM

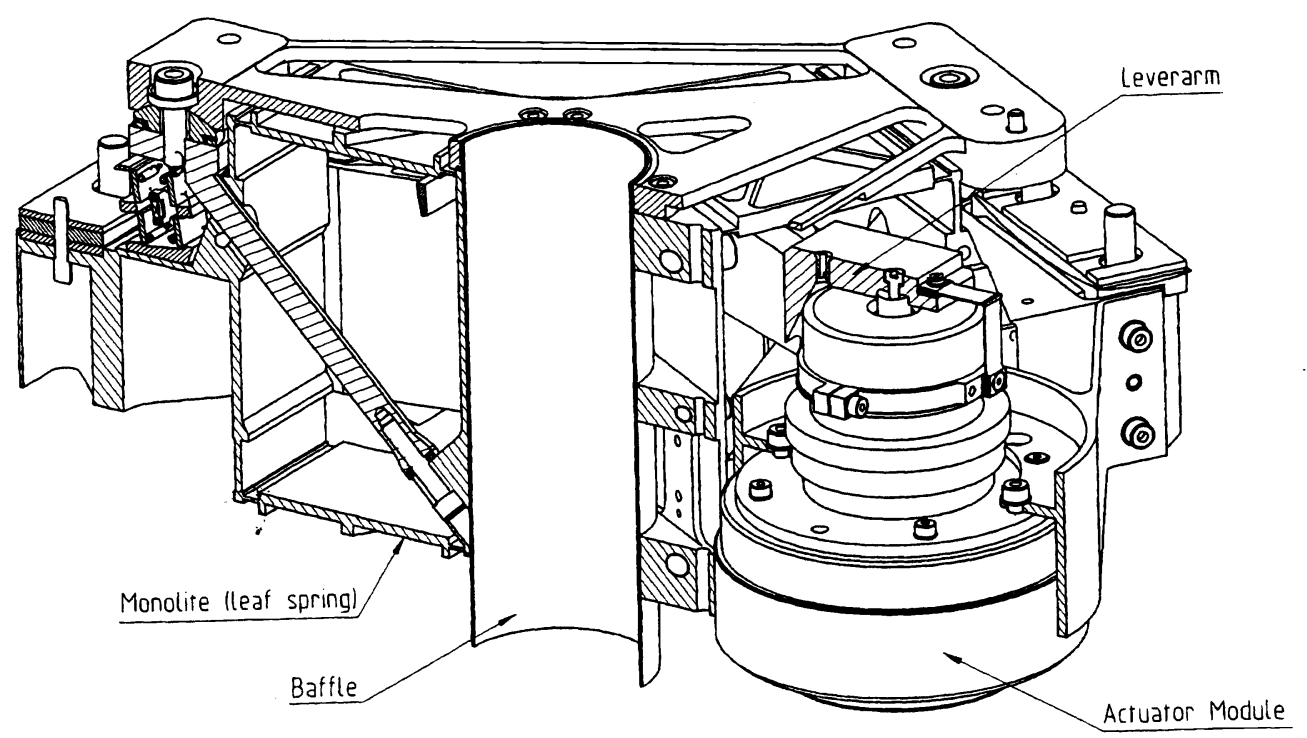

Figure 5 Cross-sectional view of the REM showing the accommodation of the Actuator Module, the Lever Arm, a Monolithic Leafspring and the Baffle for optical beam passage 
In more detail the design of the leafspring configuration fulfills the following design criteria:

- The dimensional stability meets the requirements.

- The design is optimized for low mass.

- The maximum stresses, which occur both during launch and at the end of stroke, are about $200 \mathrm{MPa}$, which is safely below the proof stress of $900 \mathrm{MPa}$.

- Adequate lateral stiffness and strength.

Due to the required stiffness and strength, the force to move the moving body from its central position to the extremes of $1.2 \mathrm{~mm}$ is approximately $500 \mathrm{~N}$, imposing the need for a high-force actuator.

The M2M3 mirror assembly and its interfaces are located at the outside of the REM volume, while the REM moving body is located at the inside. In order to provide a mechanical interface, the moving body is extended with a top bracket. This bracket is connected to the moving body in the center and via additional support via three rods. The top bracket shape and interconnection method are optimized by FE-modelling for the lowest mass and adequate stiffness. baffle.

In the center of the moving body, a black anodized aluminum cylinder is incorporated, which acts as a straylight

\subsection{ACTUATOR MODULE}

The actuator consists, besides a housing, of the following components:

- A stepper motor.

- A gearbox, to amplify the motor torque.

- A screw/spindle system to transform a rotation into a linear motion and a force.

- A mechanical end stop.

Figure 5 shows in which manner the Actuator Module fits within the REM design. The available envelope and the inevitable volume of the three monolithic leafsprings impose the need to design the module in a compact manner. Details of the actuator design are shown in figure 6.

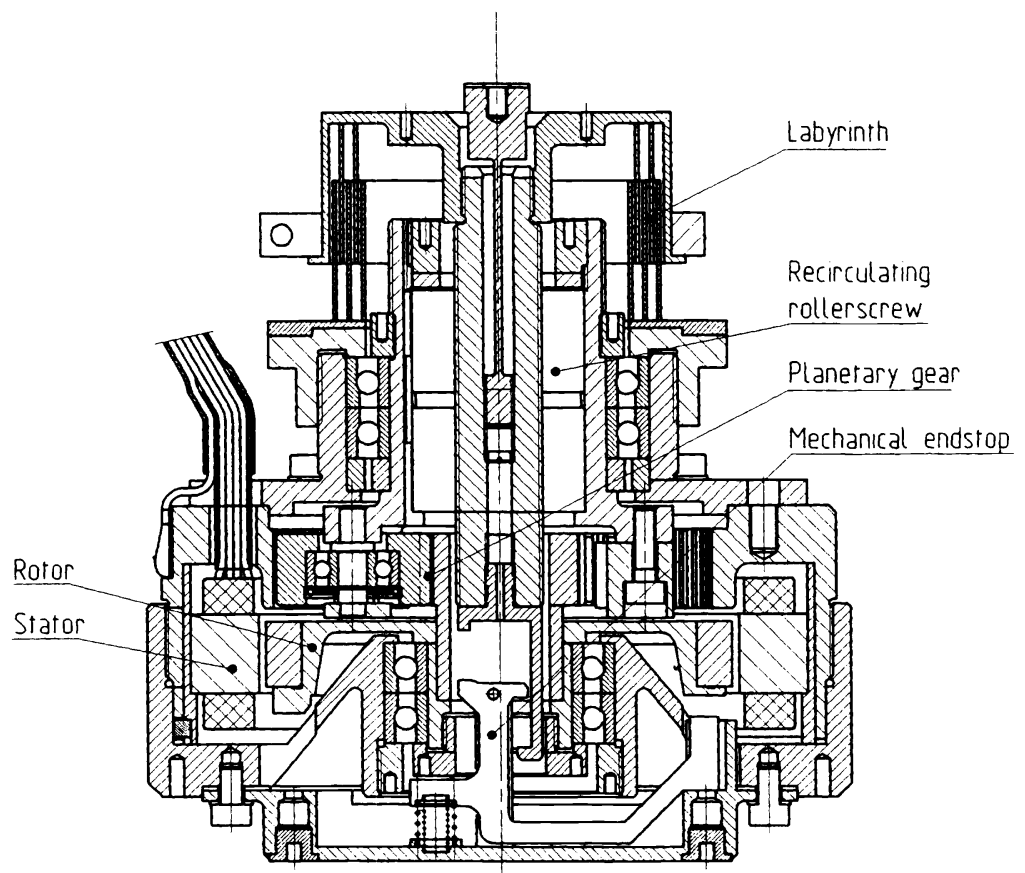

Figure 6 Actuator Module 
The Actuator Module has a compact concentric design with a maximum diameter of $100 \mathrm{~mm}$ and a length of 123 $\mathrm{mm}$. The housing has a triple labyrinth seal to restrain possible debris of coatings and materials. Titanium has been used for the Actuator Module housing for reasons of low mass and CTE match with the other parts of the REM.

A high-resolution stepper motor ( $1 \%$ step), with redundant windings, of a series developed by SAGEM for space applications, is used. For this application, the motor has been optimized for maximum torque.

A planetary gear was selected as transmission because of its compact volume in combination with a low mass. The gearbox bearings are Ion-plated Lead lubricated. The gearwheels are a self lubricating combination, Vespel SP3 vs. Titanium. The shapes of the teeth of the gearwheels are optimized for low wear.

The applied screw/spindle is a 'recirculating'rollerscrew of TRANSROL SKF. This type of rollerscrew was selected by its heritage, its good mechanical properties (a.o. its high axial stiffness, low friction torque, relatively small torque increase in case of moment loads, good adhesion of dry lubricants) and its relative simplicity. This spindle is especially suitable because of the high forces it can sustain in combination with a low pitch. The Actuator Module axial stiffness is achieved by the high axial stiffness of the rollerscrew $\left(>10^{8} \mathrm{~N} / \mathrm{m}\right)$ and the relatively high axial stiffness of the selected bearings. The stroke of the spindle is $\pm 7 \mathrm{~mm}$ and is limited by the available volume.

Backdriving of the rollerscrew is prevented by the unpowered (detent) holding torque of the stepper motor which is amplified by the gearbox. With this amplified holding torque the recirculating rollerscrew is able to maintain the position of the REM, even under the high launch loads with an adequate safety margin. To maintain a proper safety margin in holding torque however, the pitch of the rollerscrew had to be limited to $\leq 1 \mathrm{~mm}$ by such limiting the stepsize of the REM.

For the recirculating rollerscrew, a (dry) lubrication system was selected in cooperation with AEA ESTL. The selected lubrication consists of Ion-plated Lead (applied to all roller screw components) plus Braycote 601 grease. These two lubricants act in a synergetic manner to enhance the lubricant lifespan, since the Ion-plated Lead effectively delays the onset of polymerization of the PFPE oil based grease.

Because of the high output force of the Actuator Module ( $>1200 \mathrm{~N})$, operation of the mechanism beyond the extremes of the stroke would cause damage to Actuator- and the Support \& Guide Module parts. For this reason, adequate mechanical end stops have to be incorporated, capable to stop the mechanism under long duration continuous powering during extreme environmental conditions. An effective solution was found by implementing a system acting on the point of lowest torque in the system, being the motor. A Vespel lever arm is introduced, which tumbles on command of the spindle and stops the motor from further rotation.

\subsection{LEVER ARM}

Coupling of the moving body of the Support \& Guide Module with the Actuator Module is realized via a dedicated lever arm. Important further tasks of the arm are the reduction of the loads on the Actuator Module (notably on the roller screw and its bearings) during launch and the amplification of the actuator force. The lever arm is connected to the frame via a Haberland hinge and to the moving body via leafsprings. Connection to the Actuator Module is also realized via a leafspring. In this manner no high lateral forces are exerted on the moving body during actuation.

The applied Haberland hinge has been dimensioned for the particular application and is manufactured by spark erosion. The performance in terms of decentering and required rotation force is better than the performance of commercially available flexural pivots. Also the resistivity against the load environment is much better. For the dimensioning of the Haberland hinge, we have used results from an earlier development ${ }^{3}$.

\subsection{MATHEMATICAL MODELLING}

In order to gain confidence in the design and to assess the design margins, to predict the REM performance, to optimize the design for mass vs. eigenfrequency and volume and to be able to assess the performance at SEVIRI system level, various mathematical models have been developed. These models are: 
- The FE-model for the Support \& Guide Module, realized in ANSYS 5.2. The Actuator Module has been incorporated in the FE-model by its characteristics, which were derived in dedicated Mathcad computations.

- A thermal mathematical model (in much detail for the Actuator Module) realized in ESATAN (MINITAN). This model was made to the detail of the individual bearings to assess forbidden or unsafe conditions (temperature gradients over bearings which may increase or decrease the initial preload).

- A dedicated mathematical model to assess the torque margin of the actuator as a function of all relevant bearing-, gearbox-, motor- and roller screw parameters.

\section{VERIFICATION- AND QUALIFICATION PROGRAM}

To verify the REM performance and to qualify the design for the specific mission requirements, an extensive test program has been carried out on all produced models. The model philosophy which was followed in the REM development program is:

- One Structural and Thermal Model (STM); only representative from mechanical- and thermal interface point of view (mass, CoG, Mol, eigenfrequencies, power dissipation, envelope and interfaces to baseplate and M2M3 mirror assembly). Since no kinematic requirements were applicable, the complex monolithic leafsprings were replaced by simpler elastic elements. This model has been delivered to the customer in October 1996.

- One Engineering and Qualification Model (EQM); on this model the complete qualification program has been carried out. This model has been delivered to the customer in July 1997.

- Three Flight Models (FM); these models are manufactured and integrated in an identical manner as the EQM. The first flight model has been delivered to the customer in February 1998. The other two models are currently in production.

For the qualification we have adopted the approach that it will be done on the complete model (EQM), without the production of breadboard models. Some crucial parts were bought from their supplier as qualified item (EEE-parts, stepper motor, bearings). The roller screw with its lubrication has been considered to be a critical element. In a dedicated test set-up at AEA ESTL (thermal/vacuum conditions, worst case moment load applied) one roller screw has been subjected to a lifetime test. The results found during this test were satisfactory for use of this particular roller screw in the REM.

The verification program which was performed to qualify the REM consisted of the following environmental tests:

- Mechanical tests (mass, CoG, MoI, dimensions).

- Electrical tests (functions, grounding resistance, isolation, motor characteristics).

- Vibration test (quasi-static-, sine- and random vibration loads along all axes).

- Thermal vacuum test (including thermal gradient test and characterization of heating due to operation).

- Interface load test (check for induced pointing errors due to baseplate and M2M3 mirror imposed forces and moment loads).

- Lifetime test.

- Zero-gravity test.

- Spin test (impact of 100 RPM satellite spin motion)

The functional- and pointing performance was checked before and after each of the environmental tests by the following measurements:

- Pointing performance (stepsize, linearity, lateral movements and -tilts).

- Torque margin checks throughout the lifetime under all environmental conditions.

- Stability budget measurements.

A dedicated test set-up has been designed to enable the high accuracy pointing measurements in the various environmental test conditions. This set-up has been commissioned in ambient conditions $\left(20^{\circ} \mathrm{C}\right)$ as well as in thermal vacuum conditions $\left(0-50^{\circ} \mathrm{C}\right)$. The test set-up is shown in figure 7 . The most important parts of the set-up are:

- A Titanium Interface ring, simulating the SEVIRI baseplate.

- A mass dummy with mass, $\mathrm{CoG}, \mathrm{MoI}$ and mechanical interface representative for the M2M3 mirror assembly.

- A measurement system consisting of 5 Linear Variable Displacement Transducer (LVDT) to measure displacements and tilts around the two most critical axes.

- A Unit Tester, to command the REM and read housekeeping data from thermistors and limit switches. 

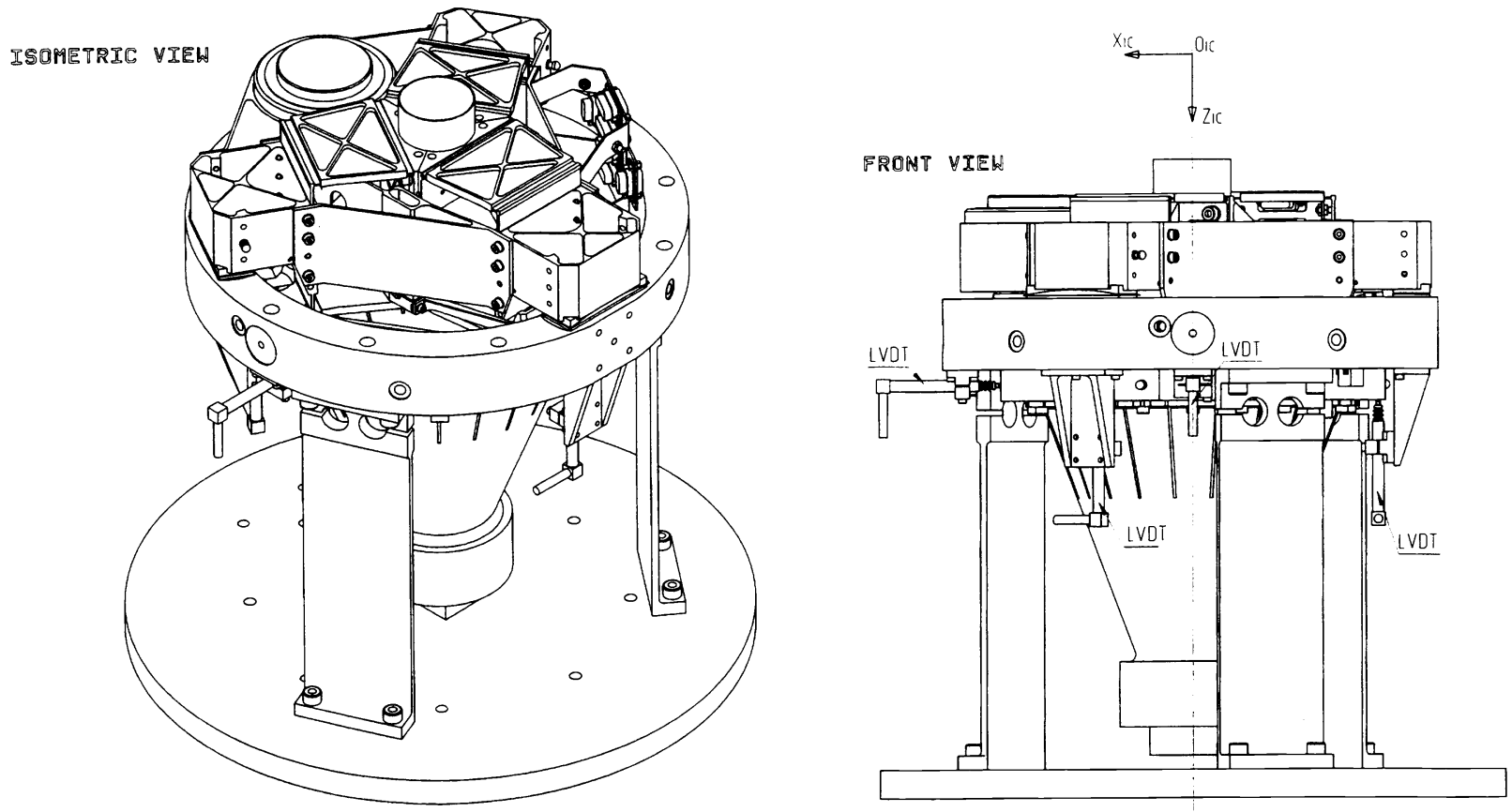

Figure 7 REM test set-up

Stability measurements have been performed using a 3-D measurement machine.

\section{PERFORMANCE}

The REM has been extensively tested in the qualification- and verification test program. The qualification program, performed on the EQM was completed successfully. All requirements except for the pointing performance in one axis direction were amply met under all relevant environmental conditions. The vibration test showed adequate eigenfrequencies and gave evidence on the integrity of the mechanical design in terms of stiffness and strength. The lifetime test showed that the envisaged number. of REM full strokes and focus actions on-ground and in-orbit can be done. Although an extended safety margin was taken for the number of cycles performed during the lifetime test, we have not found a measurable starting torque increase or decrease throughout this test. The long- and short term stability budgets were met under all conditions.

The first flight model FM1 has been subjected to an acceptance test program which was less comprehensive as the qualification test program. The relevant performance parameters however were virtually equal to those of the EQM. Table 2 gives a summary of the realized performance vs. the REM requirements. The linearity as a function of the stroke is shown in figure 8 . The achieved pointing profiles, lateral tilts and displacements as a function of the stroke are shown in figure 9. 


\begin{tabular}{|c|c|c|}
\hline Item: & Requirement: & Realized: \\
\hline Dimensions & $\begin{array}{l}\text { Diam. } 280 \mathrm{~mm} \times 123 \mathrm{~mm} \\
\text { Central hole diam. } 50 \mathrm{~mm}\end{array}$ & O.K. \\
\hline Mass & $<7.9 \mathrm{~kg}$ & $6.8 \mathrm{~kg}$. \\
\hline Power consumption & $<14.5 \mathrm{~W}$ & O.K. \\
\hline Stroke & $\pm 1.0 \mathrm{~mm}$ & O.K. \\
\hline Endstops & $\begin{array}{l} \pm 1.1 \mathrm{~mm} \\
\pm 1.2 \mathrm{~mm}\end{array}$ & O.K. \\
\hline Eigenfrequencies (launch condition) & $\begin{array}{l}>130 \mathrm{~Hz}-\text { in lateral direction } \\
>200 \mathrm{~Hz} \text { - in longitudinal direction }\end{array}$ & $\begin{array}{l}128 \mathrm{~Hz} \text { in lateral direction } \\
209 \mathrm{~Hz} \text { in longitudinal direction }\end{array}$ \\
\hline Lateral motion and rotations & $\begin{array}{l}< \pm 25 \mu \mathrm{m} \text { decenter } \\
< \pm 25 \mu \mathrm{rad} \text { spurious rotation }\end{array}$ & $\begin{array}{l} \pm 3 \mu \mathrm{m} \text { decenter } \\
\pm 10 \mu \mathrm{rad} \text { in X-direction } \\
\pm 50 \mu \mathrm{rad} \text { in } \mathrm{Y} \text {-direction }\end{array}$ \\
\hline $\begin{array}{l}\text { Overall stability (including launch- and } \\
\text { zero gravity effect and thermoelastic } \\
\text { effects of the baseplate) }\end{array}$ & $\begin{array}{l}< \pm 10 \mu \mathrm{m} \text { in axial direction } \\
< \pm 25 \mu \mathrm{m} \text { decenter } \\
< \pm 25 \mu \mathrm{rad} \text { spurious rotation }\end{array}$ & \begin{tabular}{|l}
$6 \mu \mathrm{m}$ in axial direction \\
$7 \mu \mathrm{m}$ decenter \\
$23 \mu \mathrm{rad}$ spurious rotation
\end{tabular} \\
\hline Resolution & $1.4 \mu \mathrm{m} \pm 30 \%$ & $1.33 \mu \mathrm{m} \pm 10 \%$ \\
\hline Linearity & $<10 \mu \mathrm{m}$ over the full stroke & $\pm 0.6 \mu \mathrm{m}$, hysteresis $<0.2 \mu \mathrm{m}$ \\
\hline Operational lifetime & 120 hours & $\begin{array}{l}\text { O.K., without measurable reduction in } \\
\text { Torque Margin }\end{array}$ \\
\hline Operation duration & $\begin{array}{l}\geq 2 \text { full strokes continuously } \\
\geq 9 \text { min. against mechanical endstop }\end{array}$ & O.K. \\
\hline
\end{tabular}

Table 2 Realized performance vs. REM requirements

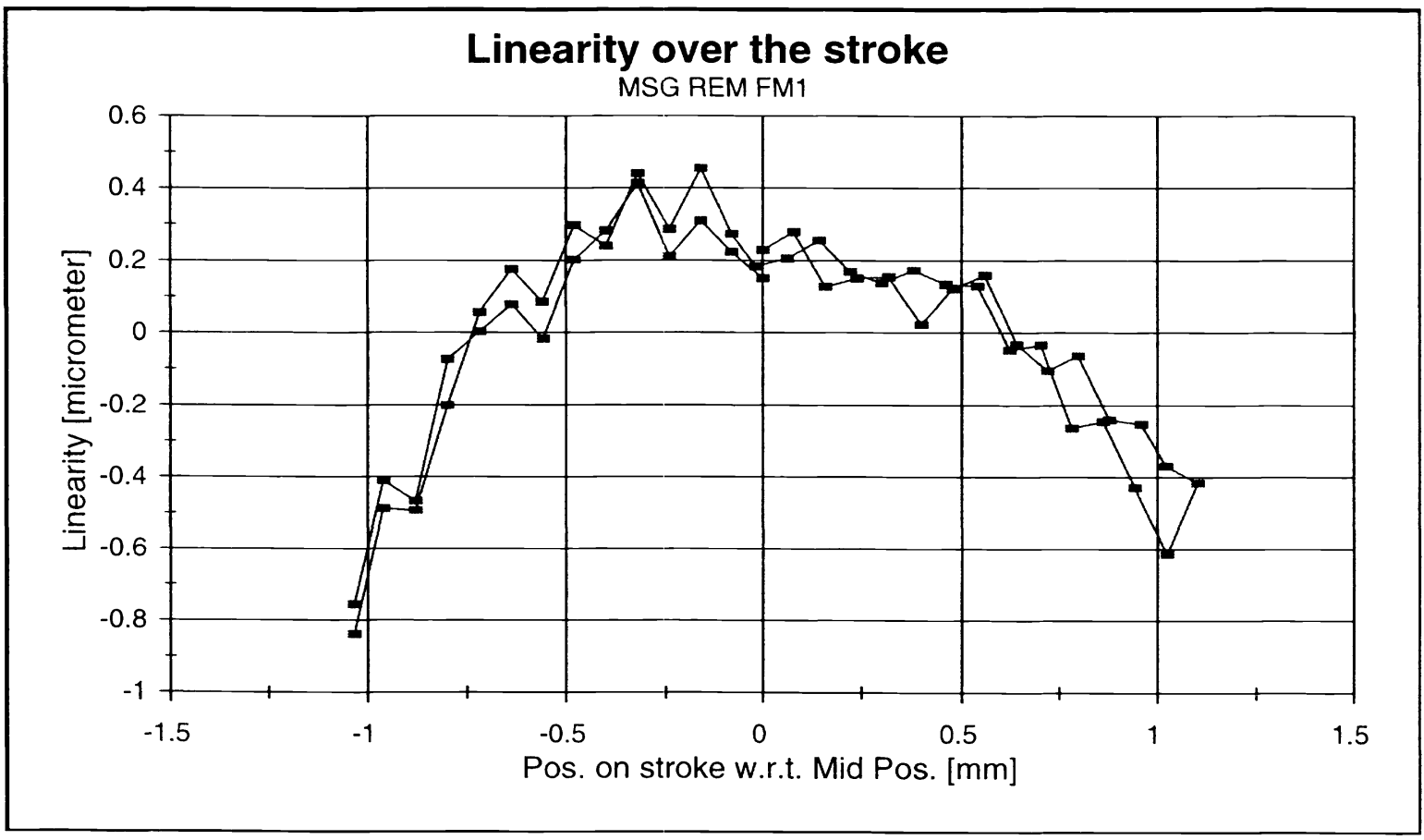

Figure 8 Linearity of the REM over the stroke 

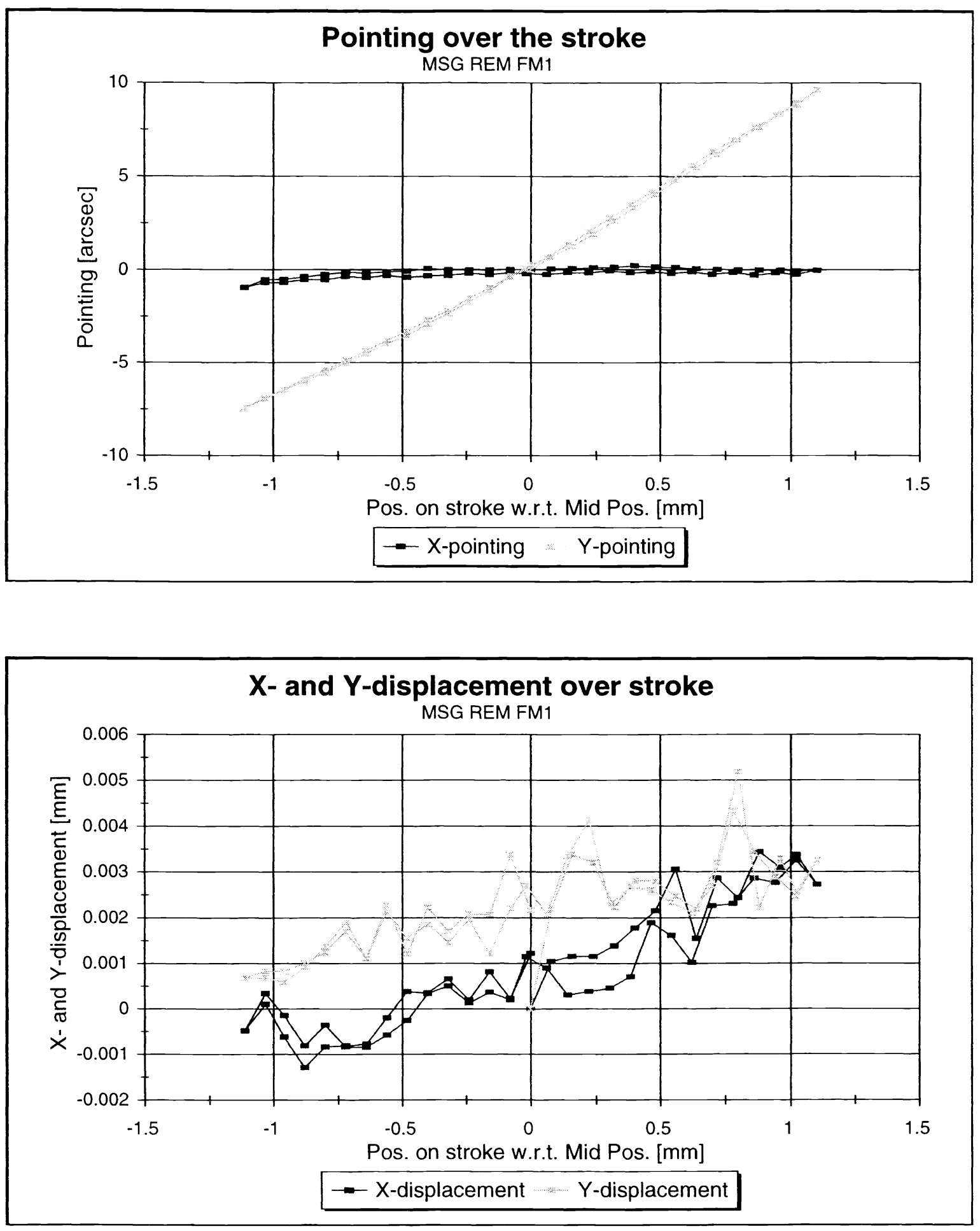

Figure 9 Pointing performance: Lateral tilts and -displacements as a function of the stroke 


\section{CONCLUSION}

A refocusing mechanism was developed and qualified for on-ground and in-orbit use. It has demonstrated to fulfill the strict requirements on pointing and stability adequately. The lowest eigenfrequency is $128 \mathrm{~Hz}$. The realized mechanism needs no clamping device. The finally achieved mass, obtained after optimization mass vs. eigenfrequency using FEmodeling, was far below the required value $(6.8 \mathrm{~kg}$ resulting $/ 7.9 \mathrm{~kg}$ required). The REM design is modular. Adaptation to requirements for similar applications will be relatively straightforward.

\section{ACKNOWLEDGMENT}

The authors wish to express their thanks to MMS-F, ESA and Aerospatiale for their reviews and support. We also like to thank ESA for the support and funding for the lifetime testing of the roller screw. The authors are further pleased to acknowledge the technical contributions of the consultants and suppliers who all participated in a fruitful manner to the REM development program. They are: AEA-ESTL - UK, Brandt Fijnmechanische Industie b.v., CELDUC Relays - France, CTT B.V., Fokker Space B.V., Jagema gereedschapmakerij b.v., KMWE PRECISIE EINDHOVEN B.V., KVV Kofmehl Vonkverspaning, MECON, RELIANCE GEAR COMPANY LIMITED - UK, SAGEM - France and TRANSROL-SKF Ball \& Roller Screws - France.

\section{REFERENCES}

1. B.C. Braam, M.P. Koster, H. Bokhove, J. Hopman, W.M.G. Courage, G. Hijkoop, M. Aguirre, A. Robinson, "The pre-development of the ARISTOTELES calibration mechanism", Fifth European Space Mechanisms and Tribology Symposium, ESA SP-344, pp. 129-136 (1993).

2. M.P. Koster, "Construction Principles", (in Dutch) Lecture book 113136 University Twente, Enschede, The Netherlands (1990).

3. M.N. Boneschanscher, "Rotation performance of monolithic flexural hinges", (in Dutch), TNO-TPD report TPDHOI-RPT-95-117 (1995). 